\title{
The application of motility studies to gastroenterological problems
}

\author{
J. J. MisiewiCZ \\ Member of Scientific Staff, M.R.C. Gastroenterology Research Unit, \\ Central Middlesex Hospital, London
}

Research Fellow, St Mark's Hospital, London

Moror activity of the human alimentary tract may be studied with a variety of techniques, including intraluminal manometry, estimation of transit rates with non-absorbable markers, cineradiography, recording of electrical potentials and in vitro pharmacological experiments. In this paper the way in which these techniques are used to investigate various pathological conditions are discussed, with emphasis on manometric studies. Technical aspects of manometry are also mentioned, but because of limitations of space this paper should not be regarded as a comprehensive review.

\section{Intraluminal manometry}

Devices commonly used for the detection of changes in intraluminal pressure $(\Delta I P)$ include open-ended tubes, balloons and radio-telemetering capsules. Each of these sensors possesses advantages and disadvantages, and the choice of a particular type depends both on the region of the gut to be examined and on the nature of the problem to be investigated.

The simplest and probably the most accurate way to measure $\Delta \mathrm{IP}$ is with narrow-bore openended tubes. The tubes are however easily blocked by mucus, faeces or mucosal folds, and must be kept patent by perfusion with fluid. Measurements of $\Delta$ IP may be made in any part of the gut with this technique.

Small $(4 \times 10 \mathrm{~mm})$ air-filled balloons (Atkinson et al., 1957) mounted on tubes, allow IP to be measured in all parts of the gut and are not subject to blocking. The amplitude of pressure waves recorded by this technique may be exaggerated when compared with open-ended tube records. This is caused by the mechanical effect of mucosal folds coming into contact with the balloon: water-filled balloons are even more likely to produce this kind of artefact. However, provided that observations are confined to comparisons between experimental periods, rather than to measurement of absolute values of IP, meaningful observations of changes in the level of gut motor-activity may be made.

Large balloons record the algebraical results of pressures in a segment of gut equal in length to the balloon; they may stimulate motor activity by their presence in the lumen of the intestine. This may be turned to advantage, for example in the investigation of the effect of antispasmodics on the background of activity induced by the balloon.

All of these techniques involve intubation, which is intensely disliked by many patients. Moreover, parts of the alimentary tract are relatively inaccessible to tubes, or may only be reached after lengthy and uncomfortable procedures. Pressure-sensitive radio-telemetering capsules are tubeless devices for intraluminal manometry. Since their introduction (Mackay \& Jacobson, 1957 ; Farrar, Zworykin \& Baum, 1957 ; Rowlands \& Wolff, 1960), radio pills have been developed to the point where they provide a reliable and accurate technique for measurement of IP (Connell et al., 1963). The radio-capsules can be readily localized in the alimentary tract (Misiewicz et al., 1968a) and is especially suitable for the study of gastric, ileal and proximal colonic motor activity. In addition to pressure, the radio-capsules also telemeter data about their movement in relation to an outside aerial (Von Ardenne \& Sprung, 1958; Smith \& Ridgeway, 1962 ; Connell et al., 1963). This movement reflects the muscle activity (MA) of the stomach, thus making it possible to measure gastric peristaltic activity (Misiewicz et al., 1968a).

Radio-telemetering may be combined with conventional techniques to record $\Delta I P$ simultaneously at several points in the gut (Misiewicz, Holdstock \& Waller, 1967). Manometry combined with synchronized cineradiography (Ramorino \& Colagrande, 1964; Painter et al., 1965) allows $\Delta$ IP and transit of gut contents to be correlated. 
Although IP can be easily measured, the analysis and interpretation of pressure records may not be straightforward. It is probably best to express the data in a numerical form, although visual inspection of records should not be neglected. Many workers have devised various indices of motility, based on laborious measurements of the pressure record (Chapman et al., 1950; Arfidsson, 1964 ; Chaudhary \& Truelove, 1961). More recently, a computer method of analysis has been developed, resulting in a more complete and speedier analysis of the pressure data (Misiewicz et al., 1968b).

The way in which motility techniques can be applied to gastroenterological problems, may be considered under the following headings:

\section{Investigation of pathological states}

The contribution of intraluminal manometry to our knowledge of oesophageal disorders has been dealt with elsewhere (Atkinson, this symposium). Suffice it to say that measurements of IP have defined the normal oesophageal function and have provided conclusive evidence for the existence of the cardiac sphincter (Fyke, Code \& Schlegel, 1956; Atkinson et al., 1957). The absence of normal peristaltic activity in the body of the oesophagus and the failure of the cardiac sphincter to relax in achalasia, have also been shown manometrically (Butlin et al., 1953; Creamer, Olsen \& Code, 1957). The situation is less clear with regard to reflux, and despite the immense quantity of manometric and radiological data accumulated on the human oesophagogastric junction, debate continues about the relative importance of sphincteric, valve-like (Creamer, Harrison \& Pierce, 1959; Edwards, 1962) or anatomical factors in maintaining the integrity of the anti-reflux barrier. Dynamic tests of cardiac sphincter strength (Winans \& Harris, 1967 ; Pope, 1967) show good separation between patients with reflux and controls and may prove of diagnostic importance. Similar techniques have been applied to the rectal sphincter (Harris, Winans \& Pope, 1966), but the contribution of mechanical and muscular forces to the preservation of anal continence is not completely settled (Harris \& Pope, 1964; Phillips \& Edwards, 1965 ; Collins et al., 1967).

Measurements of gastric IP have established the normal pattern of activity and the absence of a physiological sphincter at the pylorus (Atkinson et al., 1957). Studies of gastric emptying have established the manner in which liquid or solid meals leave the stomach; patients with duodenal ulcer tend to have a faster emptying time than normal, whilst gastric ulcer patients empty their stomachs more slowly (Hunt \& Spurrell, 1951; Hopkins, 1966; Griffith et al., 1966). George (1967) measured acid remaining in the stomach at the same time as gastric emptying. This author suggests that although patients with gastric ulcer secrete less acid than those with duodenal ulcer, the acid may remain in contact with the gastric mucous membrane for a longer period of time.

Tests of the motor activity of the colon have shown abnormalities of colonic function in conditions such as diarrhoea, constipation, the irritable colon syndrome and diverticular disease. Manometric evidence suggests that diarrhoea is associated with low, and constipation with high, levels of colonic IP activity (Connell, 1962; Wangel \& Deller, 1965; Misiewicz, Connell \& Pontes, 1966a). This apparent paradox can be explained by assuming that the contractions which produce the $\Delta \mathrm{IP}$ are non-propulsive and result in increased segmentation of the colon: a view which fits in with manometric and with radiological observations (Painter et al., 1965).

Excessive colonic pressure response to physiological or to pharmacological stimuli is a feature of diverticular disease and the irritable colos syndrome, but a study by Parks (Parks \&

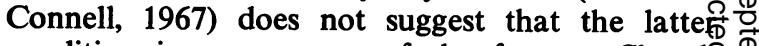
condition is a precursor of the former. Chaud음 $\stackrel{D}{\exists}$ hary \& Truelove's (1961) patients with symptoms of the irritable colon syndrome had an exaggere ated pressure response to food or prostigmine and similar observations were made by Connello Jones \& Rowlands (1965) in patients who had symptoms mainly after meals. High intracolonic pressures have long been thought to be concerned with the cause of diverticular disease. Experimental evidence for this hypothesis however has been lacking, until manometric data collected by Arfwidsson (1964) and by Painter et al. (1965) suggested that increased $\Delta \mathrm{IP}$ is found in the sigmoid colon, and especially in segments bearing the diverticula. This evidence is supported by studies of pathological material, where muscle thickening in the sigmoid region was found to be the most frequent abnormality in colons resected for diverticular disease (Morson, 1963).

Investigation of the mechanism of symptoms in individual patients

In many patients no cause for abdominal symptoms can be discovered despite extensive investigation. This group presents a difficult clinical problem, because no rational explanation can be found for the patient's discomfort, an unsatisfactory situation for the doctor and patient alike. In some of these patients 
manometric studies performed while the symptoms are present show abnormal pressure responses in various parts of the gut and Holdstock, Misiewicz \& Waller (1968) have been able to correlate bouts of abdominal pain with bursts of pressure activity in the colon or small intestine. Both symptoms and motor activity were abolished by intravenous propantheline. These observations also suggest that pain may be caused by localized areas of abnormal pressure activity. The correlation of pressure responses with pain is not proof of a causal relationship, but the authors agree with Connell et al. (1965) that intense segmenting motor activity may produce a kind of functional obstruction, which in turn leads to pain.

\section{Effects of drugs and hormones}

The effect of codeine phosphate and of laxatives on colonic transit time has been measured by Hinton (1967) with radiopaque markers in patients with diarrhoea or constipation, and in normal subjects. He demonstrated convincing changes in transit time after either drug. The method also allows for the easy estimation of stool weight and bowel frequency, so that a number of effects of a drug's action may be simply determined. A further advantage of the method is that observations are made under conditions of, and with doses routinely used in, the treatment of patients.

5-Hydroxytryptamine (5-HT, serotonin) is one of several pharmacologically active substances secreted by the tumour in the carcinoid syndrome. Although 5-HT is no longer thought to cause flushing attacks (Robertson, Peart \& Andrews, 1962), it may be the agent responsible for the diarrhoea, which is a prominent feature of the syndrome. Manometric observations of the effect of serotonin on gastro-intestinal motor activity (Misiewicz, Waller \& Eisner, 1966b) showed that the same dose of 5-HT given over the same period of time inhibited the stomach and the proximal and distal colon, but stimulated the small intestine. Similar changes were observed in patients with the carcinoid syndrome studied by those authors and by Smith, Preshaw \& Sircus (1965). These results indicate that small intestinal hyperactivity may be the cause of diarrhoea in the carcinoid syndrome.

When the motor effects of hormones are measured, it may be better to use intravenous infusions in preference to injections of the material. If possible, attempts should be made to monitor a response the magnitude of which is known under physiological conditions. Ingestion of meals has been shown to stimulate gastric acid G secretion maximally (Rune, 1966), and therefore Misiewicz et al. (1967) measured the motor responses of the human alimentary tract to infusions of pentagastrin at maximal dose levels. Under the conditions of the study, pentagastrin had no consistent effect upon $\Delta I P$, except in the gastric antrum, which was stimulated. This means that the same chemical transmitter may affect both the motor and secretory gastric function, but that gastrin may not be directly concerned in the mediation of the gastrocolic reflex.

\section{In vitro pharmacological studies}

The introduction of in vitro techniques to the study of human gastro-intestinal muscle is an important advance. Marked differences often exist between man and other species: for example isolated human gastric muscle is not very sensitive to 5-HT (Fishlock, Parks \& Dewell, 1965 ; Misiewicz et al., 1966b), whilst gastric muscle in the rat is highly sensitive (Vane, 1957). Further, although effects of drugs and hormones should always be investigated in patients, the mechanism of action and the location of receptor sites can often be unravelled only by in vitro experiments. The degree of correlation between in vitro and in vivo observations is encouraging (Misiewicz et al., 1966b, 1967 ; Bennett, Misiewicz \& Waller, 1967b).

The in vitro technique is used to study the responses of normal or abnormal tissue. Ellis, Trounce and their colleagues have demonstrated pharmacologically the denervation of the oesophagus in achalasia of the cardia (Trounce et al., 1957 ; Ellis et al., 1959). Other workers have examined responses of normal human gut muscle to a range of pharmacological agents (Fishlock \& Parks, 1963 ; Fishlock et al., 1965 ; Bucknell \& Whitney, 1964 ; Bennett, 1965 ; Bennett \& Whitney, 1966). These, and other, studies, demonstrate marked regional differences in the responses to substances which act upon the intrinsic nerves, ganglia, or upon receptors in, or on, the muscle cells. Bennett \& Whitney (1966) in a pharmacological survey of the human gastro-intestinal tract have emphasized these differences, and have suggested how they can be related to the known functions of the stomach, duodenum, small intestine and colon.

Experiments on normal tissue may be relevant to pathological states; the studies with serotonin in relation to the carcinoid syndrome have already been mentioned. It appears that bradykinin may be released both in the carcinoid and in the dumping syndrome (Zeitlin \& Smith, 1966) and complex effects of this polypeptide on the 
isolated large and small intestinal muscle have been described by Fishlock (1966). Finally, in vitro experiments may suggest new lines of investigation. Prostaglandin is released from the rat stomach when nerves in its wall are stimulated (Bennett, Friedman \& Vane, 1967b) and has now been shown to contract human longitudinal gastric muscle in vitro (Bennett, Murray \& Wyllie, 1968). It may, therefore, be important in the control of human gastric motor activity.

\section{Conclusion}

Applications of the various techniques that are available for the study of gut motor activity have been briefly reviewed in the context of gastrointestinal disease. With the possible exception of achalasia, these methods are not yet suitable for unequivocal diagnostic tests, but they are invaluable in the investigation of a wide range of gastro-intestinal diseases, in the study of individual patients and in research into fundamental problems of gut physiology.

\section{References}

Arfwidsson, S. (1964) Pathogenesis of multiple diverticula of the sigmoid colon in diverticular disease. Acta Chir. Scand. Suppl. 342.

Atkinson, M., Edwards, D.A.W., Honour, A.J. \& Rowlands, E.N. (1957) Comparison of cardiac and pyloric sphincters: a manometric study. Lancet, ii, 918.

BENNETT, A. (1965) A pharmacological investigation of human isolated ileum. Nature (Lond.), 208, 1289.

Bennett, A., FriedmanN, C.A. \& VANe, J.R. (1967a) Release of prostaglandin $\mathrm{E}_{1}$ from the rat stomach. Nature (Lond.), 216, 873.

Bennett, A., Misiewicz, J.J. \& Waller, S.L. (1967b) Analysis of the motor effects of gastrin and pentagastrin on the human alimentary tract in vitro. Gut, 8, 470.

Bennett, A., Murray, J.G. \& Wyllie, J.H. (1968) Occurrence of prostaglandin $E_{2}$ in the human stomach and a study of its effects on human isolated gastric muscle. Brit. J. Pharmac. Chemother. 32, 339.

BenNetT, A. \& Whitney, B. (1966) A pharmacological study of the motility of the human gastrointestinal tract. Gut, $1,307$.

BuCKNell, A. \& WhitNey, B. (1964) A preliminary investigation of the pharmacology of the human isolated taenia coli preparation. Brit. J. Pharmacol. 23, 164.

Butin, J.W., Olsen, A.M., Moersch, H.J. \& Code, C.F. (1953) A study of esophageal pressures in normal persons and patients with cardiospasm. Gastroenterology, 23, 278.

Chapman, W.P., Rowlands, E.N., Taylor, A. \& Jones, C.M. (1950) Multiple balloon kymograph recording of variations in motility of the upper small intestine in man during long observation periods before and after placebo administration. Gastroenterology, 15, 341.

Chaudhary, N.A. \& Truelove, S.C. (1961) Human colonic motility: a comparative study of normal subjects, patients with ulcerative colitis and patients with the irritable bowel syndrome. Gastroenterology, 40, 1.

Collins, C.D., Duthie, H.L., Shelley, T. \& Whittaker, G.E. (1967) Force in the anal canal and anal continence. Gut, 8, 354.
Connell, A.M. (1962) The motility of the pelvic colon. II Paradoxical motility in diarrhoea and constipation. Gut, 3, 342.

Connell, A.M., Jones, F.A. \& Rowlands, E.N. (1965) Motility of the pelvic colon. IV. Abdominal pain associated with colonic hypermotility after meals. Gut, 6, 105.

Connell, A.M., MCCall, J., Misiewicz, J.J. \& Rowlands, $\overrightarrow{\overrightarrow{\vec{F}}}$ E.N. (1963) Observations on the clinical use of radiopills, Brit. med. J. ii, 771.

Creamer, B., Harrison, G.K. \& Pierce, J.W. (1959)흐 Further observations on the gastro-oesophageal junction. Thorax, 14, 132.

Creamer, B., Olsen, A.M. \& Code, C.F. (1957) The® esophageal sphincters in achalasia of the cardia (cardio-es spasm). Gastroenterology, 33, 293.

EDWARDS, D.A.W. (1962) The 'raspberry' or 'flutter' valve. in the anti-reflux mechanism. Surgical Physiology of the $\overrightarrow{\vec{A}}$ Gastro-Intestinal Tract, p. 24. Royal College Surgeons, $\vec{\omega}$ Edinburgh.

Ellis, F.G., Kauntze, R., Nightingale, A. \& Trounce J.R. (1959) Further studies in achalasia of the cardia. 3 Quart. J. Med. 29, 305.

FARRAR, J.T., ZWORYKIN, V.K. \& BAUM, J. (1957) Pressure-A sensitive telemetering capsule for study of gastrointestinalic motility. Science, 126, 975.

Fishlock, D.J. (1966) Effect of bradykinin on the human isolated small and large intestine. Nature (Lond.), 212, 1533.

Fishlock, D.J. \& PARKs, A.G. (1963) A study of human colonic muscle in vitro. Brit. med. J. ii, 666.

Fishlock, D.J., Parks, A.G. \& Dewell, J.V. (1965) Acti五依 of 5 hydroxytryptamine on the human stomach, dif denum and jejunum in vitro. Gut, 6, 338.

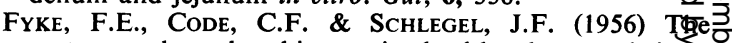
gastro-esophageal sphincter in healthy human beings. Gastroenterologia (Basel), 86, 135.

GeORGE, J.D., (1967) New clinical method for measuring the rate of gastric emptying: the double sampling test med. Gut, 9, 237.

Griffith, G.H., Owen, G.M., Kirkman, S. \& Shields, (1966) Measurement of rate of gastric emptying using chromium-51. Lancet, i, 1244.

HARRIS, L.D. \& POPE, C.E. (1964) 'Squeeze' vs. resistance; 워 an evaluation of the mechanism of sphincter competence. $\frac{\mathrm{Q}}{\mathbb{Q}}$ J. clin. Invest. 43, 2272.

Harris, L.D., Winans, C.S. \& Pope, C.E. (1966) Deter- $\overrightarrow{\vec{\sigma}}$ mination of yield pressures: A method for measuring anal sphincter competence. Gastroenterology, 50, 754.

Hinton, J.M. (1967) Laxatives and anti-diarrhoeal agents Transit studies. Proc. roy. Soc. Med. 60, 9.

Holdstock, D.J., Misiewicz, J.J. \& WAller, L. (1968)을 Correlation between intraluminal pressures and abdominal pain. Gut, (In press).

HopkINs, A. (1966) The pattern of gastric emptying: a new view of old results. J. Physiol. (Lond.), $182,144$.

Hunt, J.N. \& Spurrell, W.R. (1951) The pattern of emptying of the human stomach. J. Physiol. (Lond.), 113, 157.

MACKAY, R.S. \& JACOBSON, B. (1957) Endoradiosonde. Nature (Lond.), 179, 1239.

Misiewicz, J.J., Connell, A.M. \& Pontes, F. (1966a) Comparison of effects of meals and prostigmine on the $N$ proximal and distal colon in patients with and without diarrhoea. Gut, 7, 468.

Misiewicz, J.J., Waller, S.L. \& Eisner, M. (1966b) Motor N responses of human gastrointestinal tract to 5-hydroxy- $\omega$ tryptamine in vivo and in vitro. Gut, 7, 208.

Misiewicz, J.J., Holdstock, D.J. \& WAlleR, S.L. (1967)e Motor responses of the human alimentary tract to near maximal infusions of pentagastrin. Gut, 8, 463. 
Misiewicz, J.J., Waller, S.L., FoX, R.H., Goldsmith, R. \& HUNT, T.J. (1968a) The effect of elevated body temperature and of stress on the motor activity of stomach and colon in man. Clin. Sci. 34, 149.

Misiewicz, J.J., Waller, S.J., Healy, M.J.R. \& Piper, E.A. (1968b) Computer analysis of intraluminal pressure records. Gut, 9232.

Morson, B.C. (1963) The muscle abnormality in diverticular disease of the sigmoid colon. Brit. J. Radiol. 36, 385.

Parks, A.G. \& ConNell, A.M. (1967) The natural history of diverticular disease of the colon. Gut, 8634 .

Painter, N.S., Truelove, S.C., Ardran, G.M. \& Tuckey, M. (1965) Segmentation and the localisation of intraluminal pressures in the human colon, with special reference to the pathogenesis of colonic diverticula. Gastroenterology, 49, 169.

Phillips, S.F. \& Edwards, D.A.W. (1965) Some aspects of anal continence and defaecation. Gut, 6, 396.

Pope, C.E., II (1967) A dynamic test of sphincter strength: its application to the lower oesophageal sphincter. Gastroenterology, 52, 779.

Ramorino, M.L. \& Colagrande, C. (1964) Preliminary studies with telemetering capsules and synchronised fluorocinematography. Amer. J. dig. Dis. 28, 534.

Robertson, J.I.S., Peart, W.S. \& Andrews, T.M. (1962) The mechanism of facial flushes in the carcinoid syndromes. Quart. J. Med. 31, 103.

Rowlands, E.N. \& WolfF, H. (1960) The radio pill, telemetering from the digestive tract. Brit. Commun. Electron. 7, 598.
RUNE, S.J. (1966) Comparison of the rates of gastric acid secretion in man after ingestion of food and after maximal stimulation with histamine. Gut, 7, 344.

Smith, A.M. \& Ridgeway, M. (1962) The use of telemetering capsules in disorders of the alimentary tract. Gut, 3, 366.

Smith, A.N., Preshaw, R.M. \& Sircus, W. (1965) Clinical features in patients with the carcinoid syndrome. Gastroenterology, 48, 738 .

Trounce, J.R., Deuchar, D.C., Kauntze, R. \& Thomas, G.A. (1957) Studies in achalasia of the cardia. Quart. J. Med. 26, 433.

WANGel, A.G. \& Deller, D.J. (1965) Intestinal motility in man. III. Mechanisms of constipation and diarrhoea with particular reference to the irritable colon syndrome. Gastroenterology, 48, 69.

WinaNS, C.S. \& HARRIS, L.D. (1967) Quantitation of lower oesophageal sphincter competence. Gastroenterology, 52 , 773.

VANE, J.R. (1957) A sensitive method for the assay of 5-hydroxytryptamine. Brit. J. Pharmac. 17, 465.

Von Ardenne, M. \& Sprung, H.B. (1958) Über einen verschluckbaren Intestinalsender. Naturwissenschaften, 45, 154.

ZeItlin, I.J. \& SMith, A.N. (1966) 5-hydroxyindoles and kinins in the carcinoid and dumping syndromes. Lancet, ii, 986 . 